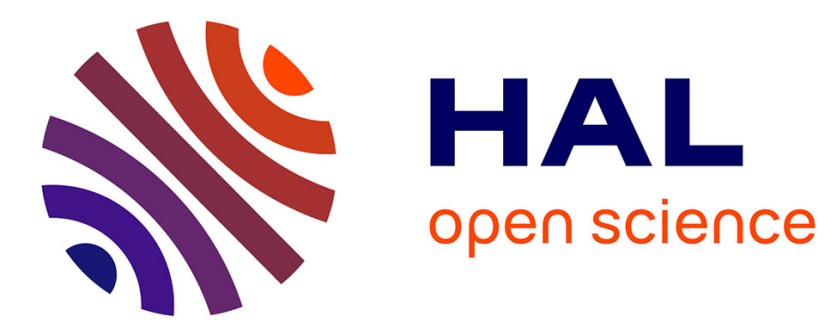

\title{
Theoretical study of hydrogen bond interactions of fluvastatin with -carrageenan and -carrageenan
}

\author{
Anastasios G. Papadopoulos, Michael P. Sigalas
}

\section{To cite this version:}

Anastasios G. Papadopoulos, Michael P. Sigalas. Theoretical study of hydrogen bond interactions of fluvastatin with -carrageenan and -carrageenan. Journal of Molecular Modeling, 2010, 17 (7), pp.1669-1678. 10.1007/s00894-010-0878-2 . hal-00636637

\section{HAL Id: hal-00636637 \\ https://hal.science/hal-00636637}

Submitted on 28 Oct 2011

HAL is a multi-disciplinary open access archive for the deposit and dissemination of scientific research documents, whether they are published or not. The documents may come from teaching and research institutions in France or abroad, or from public or private research centers.
L'archive ouverte pluridisciplinaire HAL, est destinée au dépôt et à la diffusion de documents scientifiques de niveau recherche, publiés ou non, émanant des établissements d'enseignement et de recherche français ou étrangers, des laboratoires publics ou privés. 


\title{
Theoretical study of hydrogen bond interactions of fluvastatin with $\boldsymbol{l}$-carrageenan and $\lambda$-carrageenan
}

Received: 03.09.2010 / Accepted: 08.10.2010

Anastasios G. Papadopoulos and Michael P. Sigalas ${ }^{\bigotimes}$

Laboratory of Applied Quantum Chemistry, Department of Chemistry, Aristotle University of Thessaloniki, 54124 Thessaloniki, Greece

${ }^{\circledR}$ Tel: +23 10 997815; Fax: +23 10 997738; Email: sigalas@chem.auth.gr

\begin{abstract}
The binding of the reductase inhibitor drug fluvastatin, hydroxy-3-methylglutaryl coenzyme A, with the hydrophilic $t$ - or $\lambda$-carrageenan polymers, serving as potential controllers of the drug's release rate, have been studied at the density functional level of theory with the B3LYP exchange correlation functional. Three low energy conformers of fluvastatin have been calculated. The vibrational spectroscopic properties calculated for the most stable conformer were in satisfactory agreement with the experimental data. A series of hydrogen bonded complexes of the most stable conformer of fluvastatin anion with low molecular weight models of the polymers have been fully optimized. In almost all, intermolecular H-bonds are formed between the sulfate groups of $l$ - or $\lambda$-carrageenan and fluvastatin's hydroxyls, resulting in a red shift of the fluvastatin's $\mathrm{O}-\mathrm{H}$ stretching vibrations. Cooperative intramolecular $\mathrm{H}$-bonds within fluvastatin or $t$-, $\lambda$-carrageenan are also present. The BSSE and ZPE corrected interaction energies were estimated in the range $281-318 \mathrm{~kJ} \mathrm{~mol}^{-1}$ for $\iota^{-}$ carrageenan - fluvastatin and $145-200 \mathrm{~kJ} \mathrm{~mol}^{-1}$ for $\lambda$-carrageenan - fluvastatin complexes. The electron density $\left(\rho_{\mathrm{bcp}}\right)$ and Laplacian $\left(\nabla^{2} \rho_{\mathrm{bcp}}\right)$ properties at critical points of the intermolecular hydrogen bonds, estimated by AIM (atoms in molecules) calculations, have a low and positive character $\left(\nabla^{2} \rho_{\mathrm{bcp}}>0\right)$, consistent with the electrostatic character of the hydrogen bonds. The structural and energetic data observed, as well as the extent of the red shift of the fluvastatin's $\mathrm{O}-\mathrm{H}$ stretching vibrations upon complex formation and the properties of electron density show a stronger binding of fluvastatin to $t$ - than to $\lambda$-carrageenan.
\end{abstract}


Keywords Fluvastatin $\cdot{ }$-Carrageenan $\cdot \lambda$-Carrageenan $\cdot$ Hydrogen bonding $\cdot$ Density functional theory $\cdot$ AIM 


\section{Introduction}

Hydrogen bonds (H-bonds) play a vital role in chemical, physical, biological and technological processes. While many experimental and theoretical studies have been directed toward understanding $\mathrm{H}$-bonding, it remains an area of active research. An important application of hydrogen bonded complexes is the solid dispersion systems of drugs into inert polymer matrices, primarily aiming at the optimization of the dissolution rate of poorly soluble drugs [1, 2], as well as to control the drug's release rate [3]. As in such systems the drug molecules bind to the polymer with van der Waals interactions or $\mathrm{H}$-bonds, the nature and strength of the interactions of a drug and the polymers are of particular importance [4-6]. Continuing our work on the theoretical study of $\mathrm{H}$-bond interactions between drugs and hydrophilic polymers used as excipients in drug formulation, [7, 8] we present here a density functional study of the hydrogen bonding in solid dispersions of the reductase inhibitor drug fluvastatin sodium, hydroxy-3-methylglutaryl coenzyme A, with the hydrophilic $l$ - or $\lambda$ carrageenan polymers.

Fluvastatin sodium, a mevalonolactone derivative of a fluorophenyl substituted indole (Fig. 1), is a 3-hydroxy-3-methylglutaryl coenzyme A (HMG-CoA) reductase inhibitor. It belongs to an inhibitor family of drugs, commonly called statins, which have been shown to slow the progression of coronary artery disease [9] and reduce mortality from cardiovascular disease [10]. They have been suggested to have an anti-inflamatory and anti-cancer activity [11]. Some of them are also being tested against Alzheimer's disease and osteoporosis [12]. The crystal structure of fluvastatin has been solved by X-Ray crystallography [13], whereas its conformational space and hydroxy acid-lactone interconversion have been studied with DFT calculations [14].

Carrageenans are linear, sulfated polysaccharides (galactans) extracted from various species of the red seaweed Rhodophyta $[15,16]$. The carrageenan backbone is based on the repeating disaccharide sequence of D-galactopyranose residues linked alternaterly in 3-linked- $\beta$-Dgalactopyranose and 4-linked- $\alpha$-D-galactopyranose units. They are classified according to the degree of the substitution that occurs on their free hydroxyl groups, which are generally either the addition of ester sulfate or the presence of the 3,6-anhydride on the 4-linked residue, and they are traditionally identified by a Greek prefix: $\iota^{-}$(iota) (mono-sulfate), $\kappa^{-}$(kappa) (disulfate), and $\lambda$ - (lambda) carrageenan (three-sulfate). Concerning the forms studied herein and 
shown in Fig. 1, $l$-carrageenan is composed by 3 -linked- $\beta$-D-galactopyranose-4-sulfate $(G 4 S)$ and 4'-linked-3',6'-anhydro- $\alpha$-D-galactopyranose-2-sulfate (GA2S), whereas $\lambda$-carrageenan by 3-linked- $\beta$-D-galactopyranose-2-sulfate $\quad(G 2 S) \quad$ and $\quad$ 4'-linked-3',6'-anhydro- $\alpha$-Dgalactopyranose-2,6-disulfate $(G 2 S 6 S)$.

Carrageenans have the ability to bind considerable quantities of materials. Besides their usage in food, ceramic, anti-ice fluids, paper and textile industries [17-20], complexes between carrageenan and drug molecules have been proved to control the drug's release rate and, thus, carrageenans, as well as carrageenan mixtures, have been used as drug carriers $[3,21]$.

In this article density functional theory (DFT) calculations are reported on the low energy conformation of fluvastatin and the structure of the hydrogen bonded complexes between fluvastatin and the $t$ - and $\lambda$-carrageenan polymers, in order to quantify the potential of the polymers to control the release rate of the drug. Because of the complexity of these interactions in the intact polymer our approach was to study the interaction of the drug with low molar mass molecules chosen to model each polymer. The key vibrational spectroscopy data of both fluvastatin and fluvastatin-polymer complexes indicative of the H-bond interactions responsible for the complexes' formation and the strength of the interactions calculated by means of the fluvastatin-polymer interaction energies are presented. Furthermore, the topological description of the electronic density concerning the observed hydrogen bonds has been studied by using the atoms in molecules theory (AIM).

\section{Computational methods}

Density functional theory (DFT) full geometry optimizations of the studied molecules and the H-bonded complexes have been carried out using the Gaussian 03W suite of programs [22]. The hybrid method was applied (B3LYP) with Becke's three-parameter functional [23] and the nonlocal correlation is provided by the LYP expression [24]. The basis set used was 6-31G $[25,26]$. In order to achieve a better description of the H-bond the basis set for the atoms of the groups involved, that is hydroxyl group $(\mathrm{OH})$ of fluvastatin, and the sulfate groups $\left(\mathrm{OSO}_{3}\right)$ of $l$ - and $\lambda$-carrageenan model, has been augmented to $6-31 \mathrm{G}++(\mathrm{d}, \mathrm{p})$. Harmonic frequency calculations were performed for all the optimized structures to establish that the stationary 
points found are minima. Vibrational frequency values in the harmonic approximation were scaled according to the prescriptions found in the literature [27].

In calculating the interaction energy in the hydrogen-bonded complexes studied, we accounted for the basis set superposition error (BSSE) by recalculating the monomer energies using the full dimer basis at the optimized geometry of the dimer using the counterpoise method. In this context, the BSSE corrected interaction energy of the A $\cdots \mathrm{B}$ dimer is calculated as

$$
\begin{gathered}
\Delta E(B S S E)=\Delta E+B S S E \\
\Delta E=E_{A B}^{\{A B\}}(A B)-E_{A}^{\{A\}}(A)-E_{B}^{\{B\}}(B) \\
B S S E=E_{A B}^{\{A\}}(A)+E_{A B}^{\{B\}}(B)-E_{A B}^{\{A B\}}(A)-E_{A B}^{\{A B\}}(B) \\
\Delta E(B S S E)=E_{A B}^{\{A B\}}(A B)-E_{A}^{\{A\}}(A)-E_{B}^{\{B\}}(B)+E_{A B}^{\{A\}}(A)+E_{A B}^{\{B\}}(B)-E_{A B}^{\{A B\}}(A)-E_{A B}^{\{A B\}}(B)
\end{gathered}
$$

where, $E_{A B}^{\{A B\}}(A B)$ is the energy of the optimized dimer, $E_{A}^{\{A\}}(A)$ and $E_{B}^{\{B\}}(B)$ are the energies of the monomers A and B respectively at their equilibrium geometries calculated in their own bases $\{A\}$ and $\{B\}, E_{A B}^{\{A\}}(A)$ and $E_{A B}^{\{B\}}(B)$ are the energies of the monomers $\mathrm{A}$ and B respectively at geometries found in the dimer calculated in their own bases $\{A\}$ and $\{B\}$, and $E_{A B}^{\{A B\}}(A)$ and $E_{A B}^{\{A B\}}(B)$ are the energies of the monomers $\mathrm{A}$ and $\mathrm{B}$ respectively at geometries found in the dimer calculated with the full basis of the dimer $\{A B\}$ [28-30].

Analysis of the electronic charge density $(\rho)$ and its Laplacian $\left(\nabla^{2} \rho\right)$ was performed by means of the theory of atoms in molecules (AIM) proposed by Bader and coworkers [31-34]. According to this theory, when two neighboring atoms are chemically bonded, a bond critical point (bcp) appears between them, where the charge density is a minimum at $r_{\mathrm{c}}$ along the bond path $\left(\nabla \rho_{\mathrm{bcp}}=0\right)$ but a maximum along any orthogonal displacement. The sign of the Laplacian of the density at the bond critical point $\left(\nabla^{2} \rho_{\mathrm{bcp}}\right)$, reveals whether the charge is concentrated, as in covalent bond $\left(\nabla^{2} \rho_{\mathrm{bcp}}<0\right)$, or depleted, as in closed-shell (electrostatic) 
interactions $\left(\nabla^{2} \rho_{\mathrm{bcp}}>0\right)$. The AIM calculations were performed using the critical point option for the AIM keyword as implemented by Cioslowski [35] in Gaussian 03W program [22].

\section{Results and discussion}

\section{Molecular structure of fluvastatin}

In order to study the H-bond complexes of fluvastatin with carrageenans we first located the global minimum in the conformational space of the drug, which exhibits a tremendous conformational flexibility because of the many rotational degrees of freedom, associated with single bonds (scheme 2) and a very simple conformation analysis based on torsion angles for each bond, gives more than one million conformations. Hoffmann et al has inspected the potential energy surface of fluvastatin by means of DFT calculations and found small energetic differences between conformers [14]. Thus, in this study only the global minimum and some key conformers are presented.

The two low energy conformers of fluvastatin anion (F11, F12), shown in Fig. 2, have been located by a series of full optimizations at the B3LYP/6-31G level with the basis set of the hydroxyl and carboxyl groups augmented to 6-311++G(d,p). Each initial geometry was this of the crystallographic observed structure [13] (pdb code: 1HWI) with crucial torsion angles perturbed. The most stable conformation found, Fl1, has two cooperative H-bonds between the two hydroxyl groups and a carboxyl group of fluvastatin. A similar structure has been found as the global minimum in the previous DFT study [14]. Conformation Fl2, having also two $\mathrm{H}$-bonds, is less stable by $2 \mathrm{~kJ} \mathrm{~mol}^{-1}$. A full optimization starting from the unperturbed $\mathrm{X}$ ray structure gave structure, Fl3 (Fig. 2), which is higher in energy by $18 \mathrm{~kJ} \mathrm{~mol}^{-1}$ and is very close to the experimental structure. The relative energies and relevant optimized geometrical parameters of the resulting conformers are given in Table 1. In all conformers, the $\mathrm{C}_{6}-\mathrm{C}_{7}=\mathrm{C}_{8}-\mathrm{C}_{9}$ group departs from planarity by $32-35^{\circ}$ due to steric hindrance, whereas dihedral angles around $\mathrm{C}_{2}-\mathrm{C}_{3}, \mathrm{C}_{3}-\mathrm{C}_{4}$ and $\mathrm{C}_{4}-\mathrm{C}_{5}$ bonds show that they adopt the gauche orientations.

The harmonic vibrational frequencies of all conformation have been calculated at the same level of theory and basis set and scaled with scaling factor 0.9614 [27]. The frequencies of 
$\mathrm{O}-\mathrm{H}$ stretching vibrations for the most stable conformation Fl1 have been calculated as $v_{\mathrm{O} 1-\mathrm{H} 1}=3616 \mathrm{~cm}^{-1}$ and $v_{\mathrm{O} 2-\mathrm{H} 2}=3563 \mathrm{~cm}^{-1}$.

Although in 3,5 carboxyl diols the formation of lactone is very common at a rate which is usually $\mathrm{pH}$ dependent, at physiological $\mathrm{pH}$ and higher, the lactone form is unstable and the equilibrium favours hydrolysis to open the lactone and yield the hydroxyl acid form [36-39]. According to previous DFT calculations the lactone form is higher in energy by $25-79 \mathrm{~kJ} \mathrm{~mol}^{-}$

${ }^{1}$ [14]. Thus, in this study of hydrogen bonded complexes of fluvastatin the acidic form is used instead of the lactonic form.

\section{Hydrogen bonded complexes of fluvastatin with $t$ - and $\lambda$-carrageenan polymers.}

The present reliability of high precision quantum mechanical calculations gives us the possibility to derive meaningful predictions about the strength of interactions between drugs and polymers. However, such calculations often require much long computational time and large sized memories and thus the actual analysis tend to be restricted to relatively small system representative of the whole polymer in vacuo [6-8]. In our study we used two low molecular weight models, $\boldsymbol{l}-\mathbf{C m}$ and $\lambda-\mathbf{C m}$, of $\boldsymbol{l}$ - and $\lambda$-carrageenan polymers respectively. Their calculated as global minimum structures are shown in Fig. 3. In the model of $\lambda$ carrageenan, $\lambda-\mathbf{C m}$, there are two strong H-bonds between the hydroxyl group in the 6position of the galactopyranose-4-sulfate ring and the sulfate group in the 6'-position of the galactopyranose-2,6-disulfate ring $(\mathrm{H} \cdots \mathrm{O}=1.742 \AA)$ and between the hydroxyl group in the 3 'position of the galactopyranose-2,6-disulfate ring and the sulfate group in the 2-position of the galactopyranose-4-sulfate ring $(\mathrm{H} \cdots \mathrm{O}=2.132 \AA)$.

Initial structures of the complexes formed from the most stable conformer of fluvastatin anion (conformer Fl1) and the polymer models of $\boldsymbol{l}$ - and $\lambda$-carrageenan $(\boldsymbol{l}-\mathbf{C m}$ and $\lambda$-Cm) have been modeled, where fluvastatin acts as a hydrogen donor through hydroxyl groups or as an acceptor through hydroxylic oxygens, whereas $l$-carrageenan and $\lambda$-carrageenan acts as acceptors through oxygen atoms of the sulfate groups or donors through hydroxylic hydrogens. All trial structures have been fully optimized at the B3LYP/6-31G level by adding polarization and diffuse functions, $6-31++\mathrm{G}(\mathrm{d}, \mathrm{p})$, on the atoms involved in the H-bonds. 
The three minima found for $\boldsymbol{l}$-carrageenan - fluvastatin complex $(\boldsymbol{l}$-Cm-Fl1_a, $\boldsymbol{l}$-Cm-Fl1_b, $\boldsymbol{l}$ Cm-Fl1_c) are shown in Fig. 4 and their relative energies and geometrical parameters of the H-bonds are depicted in Table 2. In all minima the groups of $l$-carrageenan involved in intermolecular H-bonds are the sulfate group in the 2'-position of the $G A 2 S$ galactopyranose unit or the hydroxyl groups in the 2- or 6-position of the G4S galactopyranose unit. Optimization of initial complex structures with the sulfate group in the 4-position of the $G 4 S$ galactopyranose unit acting as hydrogen acceptor led to the same minima. Complex $\mathbf{l}$-CmFl1_a with two intermolecular H-bonds is the most stable. The first H-bond is this between fluvastatin's $\mathrm{O}_{1}-\mathrm{H}_{1}$ hydroxyl and the $G A 2 S-2$ '-sulfate group, whereas the second is this between fluvastatin's $\mathrm{O}_{2}-\mathrm{H}_{2}$ hydroxyl and the $G 4 S$-6-hydroxyl group of $l$-carrageenan with the latter acting as a hydrogen acceptor. The complex is further stabilized by the intramolecular hydrogen between $G 4 S$-6-hydroxyl group and the GA2S-2'-sulfate group of $t$ carrageenan. The calculated $\mathrm{H} \cdots \mathrm{O}$ distances are $1.871 \AA$, $1.917 \AA$ and $1.954 \AA$ respectively. The involvement of the hydroxyl groups of fluvastatin in $\mathrm{H}$-bonds results in an elongation of $\mathrm{O}-\mathrm{H}$ bonds and a red shift of the calculated frequencies of the $\mathrm{O}-\mathrm{H}$ stretching vibrations relative to free fluvastatin $\left(v_{\mathrm{O} 1-\mathrm{H} 1}=3395 \mathrm{~cm}^{-1}\right.$ and $\left.v_{\mathrm{O} 2-\mathrm{H} 2}=3487 \mathrm{~cm}^{-1}\right)$. In the $\boldsymbol{l}$-Cm-Fl1_b complex, which is less stable by $2 \mathrm{~kJ} \mathrm{~mol}^{-1}$, only the $G A 2 S-2^{\prime}$-sulfate group of $l$-carrageenan is involved in two H-bonds with both hydroxyls of fluvastatin, with the $\mathrm{H} \cdots \mathrm{O}$ distances being $1.862 \AA$, 1.911 A. Finally, in the less stable by $35 \mathrm{~kJ} \mathrm{~mol}^{-1}$ complex, $\mathbf{l}$-Cm-Fl1_c, intramolecular Hbonds are formed between the GA2S-2'-sulfate group and fluvastatin's $\mathrm{O}_{2}-\mathrm{H}_{2}$ and between $G 4 S$-2-hydroxyl group and fluvastatin's carboxylate, whereas the intramolecular $\mathrm{H}_{1} \cdots \mathrm{O}_{2} \mathrm{H}-$ bond found in free fluvastatin (Fl1) is also present.

In the case of the interactions between $\lambda$-carrageenan and fluvastatin three complexes were also located, namely $\lambda$-Cm-Fl1_a, $\lambda$-Cm-Fl1b and $\lambda$-Cm-Fl1_c, whose optimized structures are shown in Fig. 5 and their relative energies and geometrical parameters of the H-bonds are depicted in Table 2. In all minima the intramolecular H-bond between $G 2 S$-2-sulfate and G2S6S-3'-hydroxyl group, as well as this between G2S6S-6'-sulfate and G2S-2-hydroxyl group, both found in the free $\lambda$-carrageenan model, $\lambda-\mathbf{C m}$, are retained. In the complex $\lambda$ Cm-Fl1a, being the most stable, two intermolecular H-bonds are formed between the G2S6S6 '-sulfate group of $\lambda$-carrageenan and fluvastatin's hydroxyls with $\mathrm{H} \cdots \mathrm{O}$ distances $1.881 \AA$ and $1.897 \AA$. The red shift of the calculated frequencies of $\mathrm{O}-\mathrm{H}$ stretching vibrations of the hydroxyl groups of fluvastatin involved in H-bonds $\left(v_{\mathrm{O} 1-\mathrm{H} 1}=3424 \mathrm{~cm}^{-1}\right.$ and $v_{\mathrm{O} 2-\mathrm{H} 2}=3501 \mathrm{~cm}^{-}$ 
$\left.{ }^{1}\right)$ relative to free fluvastatin for this complex is smaller than this for $\boldsymbol{l}-\mathbf{C m}-\mathbf{F l 1 a}$, a fact that serves as an indication of a stronger binding of fluvastatin to $l$-carrageenan than to $\lambda$-carrageenan. In the complex $\lambda$-Cm-Fl1b, which is less stable by $72 \mathrm{~kJ} \mathrm{~mol}^{-1}$, the two intermolecular H-bonds are those between fluvastatin's hydroxyls and the G2S6S-2'-sulfate group of $\lambda$-carrageenan. The $\mathrm{H} \cdots \mathrm{O}$ distances are equal to $1.876 \AA$ and $1.880 \AA$. Finally, the complex with the higher energy $\left(79 \mathrm{~kJ} \mathrm{~mol}^{-1}\right), \lambda$-Cm-Fl1c, has only one intermolecular $\mathrm{H}$ bond between the $G 2 S$-2-sulfate group of $\lambda$-carrageenan and fluvastatin's $\mathrm{O}_{1}-\mathrm{H}_{1}$ hydroxyl with $\mathrm{H} \cdots \mathrm{O}$ distance are equal to $1.903 \AA$. Furthermore, besides the aforementioned intramolecular bonds within $\lambda$-carrageenan the $\mathrm{H}_{2} \cdots \mathrm{O}_{1} \mathrm{H}$-bond found in free fulvastatin (FI1) is also present.

The calculated $\mathrm{H}$-bond distances $\left(\mathrm{O}_{\mathrm{F} 11} \cdots \mathrm{O}_{1, \lambda-\mathrm{Cm}}\right)$ for the intermolecular $\mathrm{H}$-bonds between $t^{-}$ and $\lambda$-carrageenan and fluvastatin, being in the range of $2.788-2.879 \AA$ and $2.822-2.885 \AA$ respectively, are indicative of a stronger binding of fluvastastin to $l$-carrageenan. This is further confirmed by the higher interaction energy values in fluvastatin- $l$-carrageenan complexes (mean $304 \mathrm{~kJ} \mathrm{~mol}^{-1}$ ) compared to those of fluvastatin- $\lambda$-carrageenan complexes $\left(\right.$ mean $166 \mathrm{~kJ} \mathrm{~mol}^{-1}$ ), listed before and after inclusion of the BSSE correction calculated by the counterpoise method, as well as the ZPE correction, in Table 3.

The use of the Laplacian of the electron density for the determination of regions of concentration and depletion of the electron density has been applied to the classification of the atomic interactions [34]. The two general classes of atomic interactions are shared interactions and closed-shell interactions. In the shared interactions (covalent and polar bonds) the charge density is contracted towards the line of interaction linking the nuclei and the Laplacian has negative values $\left(\nabla^{2} \rho_{\mathrm{bcp}}<0\right)$. In the closed-shell interactions (hydrogen-bonds, ionic bonds, and van der Waal's interactions) the charge density is contracted towards each of the interacting nuclei, the electronic charge is depleted in the interatomic surface and the Laplacian has positive values $\left(\nabla^{2} \rho_{\mathrm{bcp}}>0\right)$. The calculated electron density $\left(\rho_{\mathrm{bpc}}\right)$ and its Laplacian $\left(\nabla^{2} \rho_{\mathrm{b}}\right)$ bepat bond critical points of the H-bonds found in the optimized complexes of fluvastatin and $t$ - and $\lambda$-carrageenan are given in Table 4 . As the magnitude of both the electron density and its Laplacian within complexes of $t$ - or $\lambda$-carrageenan group are almost the same, the discussion is restricted in the representative cases of the most stable complexes $\boldsymbol{\imath}$-Cm-Fl1a and $\lambda$-Cm-Fl1a. 
The calculated electron density properties for the H-bonds of all complexes show that the intermolecular $\mathrm{O} \cdots \mathrm{H}$ bonds have low $\rho_{\mathrm{bcp}}$ and positive $\nabla^{2} \rho_{\mathrm{bcp}}$ values, typical for closed-shell interactions as $\mathrm{H}$-bonds and indicate an electrostatic character of the $\mathrm{O}{ }^{\cdots} \mathrm{H}$ bondings [34]. Moreover, the low values of ellipticity, e, at BCPs indicate stability of the H-bonds. The $t$ Cm-Fl1a shows higher $\rho_{\mathrm{bcp}}$ and $\nabla^{2} \rho_{\mathrm{bcp}}$ values than $\lambda$-Cm-Fl1a, indicating a more electrostatic $\mathrm{O} \cdots \mathrm{H}$ bonding and increased bond strength in the fluvastatin- $l$-carrageenan complex. This correlation of $\rho_{\mathrm{b}}$ and $\nabla^{2} \rho_{\mathrm{b}}$ was first reported by Carroll and Bader [40] and confirmed later by other authors $[41,42]$.

All theoretical data reveal that $l$ - and $\lambda$-carageenan polymers form hydrogen bonded complexes with fluvastatin. Although the present study is based on low molecular weight models of the polymers, one expects analogous binding in long polymer chains. Thus, both polymers and could serve as a depot for drug, leading to a stabilization of the drug during storage as well as a prolonged release profile. As $l$-carageenan shows a stronger binding with the drug, it is expected to be a better controller of the drug's release rate. A related experimental study is in progress in our Department.

\section{Conclusions}

The molecular structure of fluvastatin was studied at B3LYP level. Three low energy conformers have been located. The vibrational properties calculated for the most stable conformer were in satisfactory agreement with the experimental data. The hydrogen bonded complexes of the most stable conformer of fluvastatin anion with low molecular weight models of $l$-carrageenan or $\lambda$-carrageenan polymers have been fully optimized. In almost all cases intermolecular H-bonds are formed between the sulfate groups of $l$ - or $\lambda$-carrageenan and fluvastatin's hydroxyls, along with cooperative intramolecular H-bonds within fluvastatin or $t$-, $\lambda$-carrageenan. The BSSE and ZPE corrected interaction energies were estimated in the range $281-318 \mathrm{~kJ} \mathrm{~mol}^{-1}$ for $t$-carageenan and $145-200 \mathrm{~kJ} \mathrm{~mol}^{-1}$ for $\lambda$-carageenan complexes. The low values of electron density $\rho_{\mathrm{bcp}}$ and positive values of the Laplacian $\nabla^{2} \rho_{\text {bcp }}$ at the intermolecular H-bonds' critical points, estimated by AIM calculations, are consistent with electrostatic character of the $\mathrm{H}$-bond. The stronger binding of fluvastatin to $t^{-}$ carageenan than to $\lambda$-carageenan, according to the structural and energetic data observed as 
well as to the extent of the red shift of the fluvastatin's $\mathrm{O}-\mathrm{H}$ stretching vibrations upon complex formation and the properties of electron density, indicates that $t$-carageenan would be a better controller of the drug's release rate.

\section{Acknowledgments}

A.G.P wishes to thank Pharmathen S.A. for its kind financial support. 


\section{References}

1. Serajuddin ATM (1999) J Pharm Sci 88:1058-1066

2. Craig DQM (2002) Int J Pharm 231:131-144

3. Gupta VK, Hariharan M, Wheatley TA, Price JC (2001) Eur J Pharm Biopharm 51:241248

4. Bogdanova S, Pajeva I, Nikolova P, Tsakovska I, Muller B (2005) Pharm Res 22:806-815

5. Gupta R, Thilagavathi R, Chakraborti AK, Bansal AK (2005) Mol Pharm 2:384-391

6. Oliveira BG, Lima MCA, Pitta IR, Galdino SL, Hernades MZ (2010) J Mol Model $16: 119-127$

7. Teberekidis VI, Sigalas MP (2007) J Mol Struct THEOCHEM 803:29-38

8. Karavas E, Georgarakis E, Sigalas MP, Avgoustakis K, Bikiaris D (2007) Eur J Pharm Biopharm 66:334-347

9. La Rosa JC, He J, Vupputuri S (1999) J Am Med Assoc 282:2340-2346

10. Almuti K, Rimawi R, Spevack D, Ostfeld RJ (2006) Int J Cardiol 109:7-15

11. Yoshida M (2003) J Atheroscler Thromb 10:140-144

12. Miida T, Hirayanna S, Nakamura Y (2004) J Atheroscler Thromb 11:253-264

13. Istvan ES, Deisenhofer J (2001) Science 292:1160-1164

14. Grabarkiewicz, T Grobelny P, Hoffmann M, Mielcarek J (2006) Org Biomol Chem 4:4299-4306

15. Piculell L (2006) Gelling carrageenans. In: Stephen AM, Phillips GO, Williams PA (eds) Food polysaccharides and their applications, $2^{\text {nd }}$ edn. Taylor and Francis Group, London, New York, pp 239-276

16. Falshaw R, Fourneaux RH, Stevenson DE (2005) Carbohyd Res 340:1149-1158

17. De Ruiter GA, Rudolph B (1997) Trends Food Sci Technol 8:389-395

18. Tye RJ (1989) Carbohyd Polym 10:259-280

19. Shchipunov YA (2003) J Colloid Interf Sci 268:68-76

20. Langendorff V, Guveliev G, Michon C, Launay B, Parker A, De Kruif CG (2000) Food Hydrocolloid 14:273-280

21. Nanaki S, Karavas E, Kalantzi L, Bikiaris D (2010) Carbohyd Res 79:1157-1167 and references therein

22. Frisch MJ, Trucks GW, Schlegel HB, Scuseria GE, Robb MA, Cheeseman JR, Montgomery JA Jr, Vreven T, Kudin KN, Burant JC, Millam JM, Iyengar SS, Tomasi J, Barone V, Mennucci B, Cossi M, Scalmani G, Rega N, Petersson GA, Nakatsuji H, Hada 
M, Ehara M, Toyota K, Fukuda R, Hasegawa J, Ishida M, Nakajima T, Honda Y, Kitao O, Nakai H, Klene M, Li X, Knox JE, Hratchian HP, Cross JB, Adamo C, Jaramillo J, Gomperts R, Stratmann RE, Yazyev O, Austin AJ, Cammi R, Pomelli C, Ochterski JW, Ayala PY, Morokuma K, Voth GA, Salvador P, Dannenberg JJ, Zakrzewski VG, Dapprich S, Daniels AD, Strain MC, Farkas O, Malick DK, Rabuck AD, Raghavachari K, Foresman JB, Ortiz JV, Cui Q, Baboul AG, Clifford S, Cioslowski J, Stefanov BB, Liu G, Liashenko A, Piskorz P, Komaromi I, Martin RL, Fox DJ, Keith T, Al-Laham MA, Peng CY, Nanayakkara A, Challacombe M, Gill PMW, Johnson B, Chen w, Wong MW, Gonzalez C, Pople JA (2003) Gaussian 03W, Revision B.02, Gaussian Inc, Pittsburgh, PA

23. Becke AD (1993) J Chem Phys 98:5648-5652.

24. Lee C, Yang W, Parr RG (1988) Phys Rev B 37:785-789

25. Raghavachari K, Pople JA, Replogle ES, Head-Gordon M (1990) J Phys Chem 94:55795596

26. Frisch MJ, Pople JA, Binkley JS (1984) J Chem Phys 80:3265-3269

27. Avci D, Atalay Y (2009) Int J Quantum Chem 109:328-341

28. (a) Boys SF, Bernardi F (1970) Mol Phys 19:553-566 (b) Davidson ER, Chakravorty SJ (1994) Chem Phys Lett 217:48-54

29. (a) Van Duijneveldt FB, Van Duijneveldt-van de Rijdt JGCM, Van Lenthe JH (1994) Chem Rev 94:1873-1885 (b) Jeziorski B, Moszynski R, Szalewicz K (1994) Chem Rev 94:1887-1930

30. Xantheas SS, (1996) J Chem Phys 104:8821-8824

31. Bader RFW, Anderson SG, Duke AJ (1979) J Am Chem Soc 101:1389-1395

32. Bader RFW, Slee TS, Cremer D, Kraka E (1983) J Am Chem Soc 105:5061-5068

33. Bader RFW, MacDougall PJ (1985) J Am Chem Soc 107:6788-6795

34. Bader RFW, MacDougall PJ, Lau CDH (1984) J Am Chem Soc 106 1594-1605

35. (a) Cioslowski J (1993) Chem Phys Lett 203:137-142. (b) Cioslowski J (1992) Chem Phys Lett 194:73-78 (c) Cioslowski J, Surjan PR (1992) THEOCHEM 255:9-33

36. Jemal M, Ouyang Z, Powell ML (2000) J Pharm Biomed Anal 23:323-340

37. Zhao JJ, Xie IH, Yang AY, Roadcap BA, Rogers JD (2000) J Mass Spectrom 35:11331143

38. Kaufman MJ (1990) Int J Pharm 66:97-106

39. Kearny AS, Crawford LF, Mehta SC, Radebaugh GW (1993) Reductase Inhibitor, CI981. Pharm Res 10:1461-1465 
40. Carroll MT, Bader RFW (1988) Mol Phys 63:387-405

41. Platts JA, Howard ST, Bracke BRF (1996) J Am Chem Soc 118:2726-2733

42. Perez-Lustres JL, Mosquera M, Klark T (2001) Phys Chem Chem Phys 3:3569-3579 


\section{Tables}

Table 1 Relative energies ${ }^{a}$ and relevant optimized geometrical parameters ${ }^{b, c}$ of fluvastatin conformers

\begin{tabular}{lccc}
\hline & Fl1 & Fl2 & Fl3 \\
\hline$\Delta \mathrm{E}$ & 0.0 & 2 & 18 \\
$\mathrm{O}_{3}-\mathrm{C}_{1}-\mathrm{C}_{2}-\mathrm{C}_{3}$ & 12.6 & -12.3 & 44.5 \\
$\mathrm{C}_{1}-\mathrm{C}_{2}-\mathrm{C}_{3}-\mathrm{C}_{4}$ & 179.2 & -179.3 & 175.7 \\
$\mathrm{C}_{2}-\mathrm{C}_{3}-\mathrm{C}_{4}-\mathrm{C}_{5}$ & -177.7 & 177.3 & 176.8 \\
$\mathrm{C}_{3}-\mathrm{C}_{4}-\mathrm{C}_{5}-\mathrm{C}_{6}$ & 171.2 & -171.4 & 56.3 \\
$\mathrm{C}_{4}-\mathrm{C}_{5}-\mathrm{C}_{6}-\mathrm{C}_{7}$ & -116.2 & 109.4 & -121.9 \\
$\mathrm{C}_{6}-\mathrm{C}_{7}=\mathrm{C}_{8}-\mathrm{C}_{9}$ & -145.5 & -147.4 & -148.0 \\
$\mathrm{C}_{8}-\mathrm{C}_{9}-\mathrm{C}_{10}-\mathrm{C}_{11}$ & 45.0 & 45.1 & 52.5 \\
$\mathrm{C}_{8}-\mathrm{N}-\mathrm{C}_{12}-\mathrm{C}_{13}$ & -122.9 & -120.7 & -121.9 \\
$\mathrm{C}_{8}-\mathrm{N}-\mathrm{C}_{12}-\mathrm{C}_{14}$ & 109.2 & 111.2 & 110.1 \\
$\mathrm{H}_{1} \cdots \mathrm{O}_{3}$ & 2.122 & 2.122 & 2.111 \\
$\mathrm{O}_{1}-\mathrm{H}_{1} \cdots \mathrm{O}_{3}$ & 129.4 & 129.4 & 125.8 \\
$\mathrm{O}_{1}-\mathrm{H}_{1}$ & 0.967 & 0.967 & 0.964 \\
$\mathrm{H}_{2} \cdots \mathrm{O}_{1}$ & 1.932 & 1.932 & \\
$\mathrm{O}_{2}-\mathrm{H}_{2} \cdots \mathrm{O}_{1}$ & 142.8 & 142.7 & \\
$\mathrm{O}_{2}-\mathrm{H}_{2}$ & 0.969 & 0.969 & \\
\hline${ }^{a}$ Energies in kJ mol & & \\
1 and 2 & & &
\end{tabular}


Table 2 Relative energies ${ }^{\alpha}$ and geometrical parameters ${ }^{b, c}$ for H-bonded complexes of fluvastatin anion with $l$-and $\lambda$-carrageenan

\begin{tabular}{|c|c|c|c|c|c|}
\hline \multicolumn{2}{|c|}{ l-Cm-Fl_1_a } & \multicolumn{2}{|c|}{ l-Cm-Fl_1_b } & \multicolumn{2}{|c|}{ l-Cm-Fl_1_c } \\
\hline$\Delta \mathbf{E}^{c}$ & $\mathbf{0 . 0}$ & $\Delta \mathbf{E}$ & 2 & $\Delta \mathbf{E}$ & 35 \\
\hline \multicolumn{6}{|c|}{ Intermolecular Hydrogen Bonds } \\
\hline $\mathbf{O}_{1}-\mathbf{H}_{1}$ & 0.981 & $\mathbf{O}_{1}-\mathbf{H}_{1}$ & 0.980 & $\mathbf{O}_{2}-\mathbf{H}_{2}$ & 0.994 \\
\hline $\mathbf{H}_{1} \cdots \mathrm{O}_{3 \mathrm{a}}$ & 1.871 & $\mathbf{H}_{1} \cdots \mathbf{O}_{1 \mathrm{a}}$ & 1.862 & $\mathbf{H}_{2} \cdots \mathbf{O}_{2 \mathrm{a}}$ & 1.881 \\
\hline $\mathbf{O}_{1} \cdots \mathbf{O}_{3 a}$ & 2.788 & $\mathbf{O}_{1} \cdots \mathbf{O}_{1 \mathrm{a}}$ & 2.868 & $\mathbf{O}_{2} \cdots \mathbf{O}_{2 a}$ & 2.858 \\
\hline $\mathrm{O}_{1}-\mathrm{H}_{1} \cdots \mathrm{O}_{3 \mathrm{a}}$ & 154.4 & $\mathbf{O}_{1}-\mathrm{H}_{1} \cdots \mathrm{O}_{1 \mathrm{a}}$ & 169.6 & $\mathbf{O}_{2}-H_{2} \cdots \mathbf{O}_{2 a}$ & 166.9 \\
\hline $\mathbf{O}_{2}-\mathbf{H}_{2}$ & 0.977 & $\mathbf{O}_{2}-\mathbf{H}_{2}$ & 0.978 & $\mathbf{O}_{4 a}-\mathbf{H}_{4 a}$ & 0.991 \\
\hline $\mathbf{H}_{2} \cdots \mathbf{O}_{2 \mathbf{a}}$ & 1.887 & $\mathbf{H}_{2} \cdots \mathbf{O}_{2 a}$ & 1.911 & $\mathbf{H}_{4 a} \cdots \mathbf{O}_{3}$ & 1.962 \\
\hline $\mathbf{O}_{2} \cdots \mathbf{O}_{2 a}$ & 2.847 & $\mathrm{O}_{2} \cdots \mathrm{O}_{2 \mathrm{a}}$ & 2.832 & $\mathbf{O}_{4 a} \cdots \mathbf{O}_{3}$ & 2.879 \\
\hline $\mathbf{O}_{2}-\mathbf{H}_{2} \cdots \mathbf{O}_{2 a}$ & 166.8 & $\mathbf{O}_{2}-\mathbf{H}_{2} \cdots \mathbf{O}_{2 \mathbf{a}}$ & 165.2 & $\mathbf{O}_{4 a}-H_{4 a} \cdots O_{3}$ & 152.7 \\
\hline \multicolumn{6}{|c|}{ Intramolecular Hydrogen Bonds } \\
\hline $\mathbf{O}_{3 \mathbf{a}}-\mathbf{H}_{3 \mathbf{a}}$ & 0.976 & & & $\mathbf{O}_{1}-\mathbf{H}_{1}$ & 0.980 \\
\hline $\mathbf{H}_{3 \mathbf{a}} \cdots \mathbf{O}_{\mathbf{1 a}}$ & 1.954 & & & $\mathbf{H}_{1} \cdots \mathbf{O}_{2}$ & 1.816 \\
\hline $\mathbf{O}_{3 \mathbf{a}} \cdots \mathbf{O}_{1 \mathbf{a}}$ & 2.874 & & & $\mathbf{O}_{1} \cdots \mathbf{O}_{2}$ & 2.704 \\
\hline $\mathrm{O}_{3 \mathrm{a}}-\mathrm{H}_{3 \mathrm{a}} \cdots \mathrm{O}_{1 \mathrm{a}}$ & 156.0 & & & $\mathrm{O}_{1}-\mathrm{H}_{1} \cdots \mathrm{O}_{2}$ & 148.9 \\
\hline \multicolumn{2}{|c|}{$\lambda$-Cm-Fl_1_a } & \multicolumn{2}{|c|}{$\lambda$-Cm-Fl_1_b } & \multicolumn{2}{|c|}{$\lambda$-Cm-Fl_1_c } \\
\hline$\Delta \mathbf{E}$ & $\mathbf{0 . 0}$ & $\Delta \mathbf{E}$ & 72 & $\Delta \mathbf{E}$ & 79 \\
\hline \multicolumn{6}{|c|}{$\overline{\text { Intermolecular Hydrogen Bonds }} \overline{\text { Heg }}$} \\
\hline $\mathbf{O}_{1}-\mathbf{H}_{1}$ & 0.986 & $\mathbf{O}_{1}-\mathbf{H}_{1}$ & 0.985 & $\mathbf{O}_{1}-\mathbf{H}_{1}$ & 0.990 \\
\hline $\mathbf{H}_{1} \cdots \mathbf{O}_{1 \mathrm{a}}$ & 1.881 & $\mathbf{H}_{1} \cdots \mathbf{O}_{8 \mathbf{a}}$ & 1.876 & $\mathbf{H}_{1} \cdots \mathbf{O}_{5 \mathbf{a}}$ & 1.903 \\
\hline $\mathbf{O}_{1} \cdots \mathrm{O}_{1 \mathrm{a}}$ & 2.822 & $\mathbf{O}_{1} \cdots \mathbf{O}_{8 \mathbf{a}}$ & 2.834 & $\mathbf{O}_{1} \cdots \mathbf{O}_{5 \mathrm{a}}$ & 2.885 \\
\hline $\mathrm{O}_{1}-\mathrm{H}_{1} \cdots \mathrm{O}_{1 \mathrm{a}}$ & 158.6 & $\mathbf{O}_{1}-\mathbf{H}_{1} \cdots \mathbf{O}_{8 \mathrm{a}}$ & 163.4 & $\mathbf{O}_{1}-\mathrm{H}_{1} \cdots \mathbf{O}_{5 \mathrm{a}}$ & 171.0 \\
\hline $\mathbf{O}_{2}-\mathbf{H}_{2}$ & 0.986 & $\mathbf{O}_{2}-\mathbf{H}_{2}$ & 0.988 & & \\
\hline $\mathbf{H}_{2} \cdots \mathbf{O}_{2 a}$ & 1.897 & $\mathbf{H}_{2} \cdots \mathbf{O}_{9 a}$ & 1.880 & & \\
\hline $\mathrm{O}_{2} \cdots \mathrm{O}_{2 \mathrm{a}}$ & 2.847 & $\mathrm{O}_{2} \cdots \mathrm{O}_{9 \mathrm{a}}$ & 2.822 & & \\
\hline $\mathrm{O}_{2}-\mathrm{H}_{2} \cdots \mathrm{O}_{2 \mathrm{a}}$ & 160.9 & $\mathrm{O}_{2}-\mathrm{H}_{2} \cdots \mathrm{O}_{9 \mathrm{a}}$ & 158.4 & & \\
\hline \multicolumn{6}{|c|}{ Intramolecular Hydrogen Bonds } \\
\hline & & & & $\mathbf{O}_{2}-\mathbf{H}_{2}$ & 0.981 \\
\hline & & & & $\mathbf{H}_{2} \cdots \mathbf{O}_{1}$ & 1.833 \\
\hline & & & & $\mathrm{O}_{2} \cdots \mathrm{O}_{1}$ & 2.706 \\
\hline & & & & $\mathrm{O}_{2}-\mathrm{H}_{2} \cdots \mathrm{O}_{1}$ & 146.5 \\
\hline $\mathrm{O}_{6 \mathrm{a}}-\mathrm{H}_{6 \mathrm{a}}$ & 0.986 & $\mathbf{O}_{6 \mathbf{a}}-\mathbf{H}_{6 \mathbf{a}}$ & 0.995 & $\mathrm{O}_{6 \mathrm{a}}-\mathrm{H}_{6 \mathrm{a}}$ & 0.993 \\
\hline $\mathbf{H}_{6 \mathbf{a}} \cdots \mathrm{O}_{3 \mathbf{a}}$ & 1.916 & $\mathrm{H}_{6 \mathrm{a}} \cdots \mathrm{O}_{3 \mathrm{a}}$ & 1.733 & $\mathrm{H}_{6 \mathrm{a}} \cdots \mathrm{O}_{3 \mathrm{a}}$ & 1.756 \\
\hline $\mathbf{O}_{6 \mathbf{a}} \cdots \mathbf{O}_{3 \mathbf{a}}$ & 2.901 & $\mathbf{O}_{6 a} \cdots \mathbf{O}_{3 a}$ & 2.722 & $\mathbf{O}_{6 a} \cdots \mathbf{O}_{3 a}$ & 2.745 \\
\hline $\mathrm{O}_{6 \mathrm{a}}-\mathrm{H}_{6 \mathrm{a}} \cdots \mathrm{O}_{3 \mathrm{a}}$ & 174.6 & $\mathbf{O}_{6 \mathrm{a}}-\mathrm{H}_{6 \mathrm{a}} \cdots \mathrm{O}_{3 \mathrm{a}}$ & 172.7 & $\mathbf{O}_{6 \mathrm{a}}-\mathrm{H}_{6 \mathrm{a}} \cdots \mathrm{O}_{3 \mathrm{a}}$ & 173.7 \\
\hline $\mathbf{O}_{7 \mathbf{a}}-\mathbf{H}_{7 \mathbf{a}}$ & 0.999 & $\mathbf{O}_{7 \mathbf{a}}-\mathbf{H}_{7 \mathbf{a}}$ & 0.993 & $\mathbf{O}_{7 \mathbf{a}}-\mathbf{H}_{7 \mathbf{a}}$ & 0.997 \\
\hline $\mathbf{H}_{7 \mathbf{a}} \cdots \mathbf{O}_{4 a}$ & 1.831 & $\mathbf{H}_{7 \mathrm{a}} \cdots \mathbf{O}_{4 \mathrm{a}}$ & 1.866 & $\mathbf{H}_{7 \mathrm{a}} \cdots \mathbf{O}_{4 \mathrm{a}}$ & 1.921 \\
\hline $\mathbf{O}_{7 \mathrm{a}} \cdots \mathbf{O}_{4 \mathrm{a}}$ & 2.778 & $\mathbf{O}_{7 \mathrm{a}} \cdots \mathbf{O}_{4 \mathrm{a}}$ & 2.820 & $\mathbf{O}_{7 \mathrm{a}} \cdots \mathbf{O}_{4 \mathrm{a}}$ & 2.885 \\
\hline $\mathbf{O}_{7 \mathrm{a}}-\mathbf{H}_{7 \mathrm{a}} \cdots \mathbf{O}_{4 \mathrm{a}}$ & $\mathbf{1 5 7 . 4}$ & $\mathbf{O}_{7 \mathrm{a}}-\mathbf{H}_{7 \mathrm{a}} \cdots \mathbf{O}_{4 \mathrm{a}}$ & 160.2 & $\mathbf{O}_{7 \mathrm{a}}-\mathbf{H}_{7 \mathrm{a}} \cdots \mathbf{O}_{4 \mathrm{a}}$ & 161.9 \\
\hline
\end{tabular}


Table 3 Interaction energy $\left(\mathrm{kJ} \mathrm{mol}^{-1}\right)$ of $\mathrm{H}$-bonded complexes of fluvastatin anion with $l^{-}$ Carrageenan and $\lambda$-Carrageenan

\begin{tabular}{cccc}
\hline & $\Delta E$ & $\Delta E+\mathrm{BSSE}$ & $\Delta E+\mathrm{BSSE} \Delta \mathrm{ZPE}^{a}$ \\
\hline $\boldsymbol{l}$-Cm_Fl1_a & -383 & -318 & -318 \\
$\boldsymbol{\lambda}$-Cm_Fl1_b & -381 & -316 & -314 \\
$\boldsymbol{\lambda}$-Cm_Fl1_c & -345 & -282 & -281 \\
$\boldsymbol{\lambda}$-Cm_Fl1_a & -284 & -201 & -200 \\
$\boldsymbol{\lambda}$-Cm_Fl1_b & -199 & -154 & -152 \\
$\boldsymbol{\lambda}$-Cm_Fl1_c & -189 & -146 & -145 \\
\hline
\end{tabular}

${ }^{a} \mathrm{ZPE}$ calculated as $0.9614 \Sigma h v_{\mathrm{i}} / 2$. 
Table 4 Properties of the electron density, $\rho_{\text {bcp }}$, at H-bond critical points, its Laplacian, $\nabla^{2} \rho_{\text {bcp }}$, and ellipticity, $\varepsilon$, for H-bonded complexes of fluvastatin anion with $t$ - and $\lambda$-carrageenan. ${ }^{a, b}$

\begin{tabular}{|c|c|c|c|c|c|c|c|c|c|c|c|}
\hline \multicolumn{4}{|c|}{ l-Cm-Fl1_a } & \multicolumn{4}{|c|}{ l-Cm-Fl1_b } & \multicolumn{4}{|c|}{ l-Cm-Fl1_c } \\
\hline & $\rho_{\mathrm{bcp}}$ & $\nabla^{2} \rho_{\mathrm{bcp}}$ & $\varepsilon$ & & $\rho_{\mathrm{bcp}}$ & $\nabla^{2} \rho_{\mathrm{bcp}}$ & $\varepsilon$ & & $\rho_{\mathrm{bcp}}$ & $\nabla^{2} \rho_{\mathrm{bcp}}$ & $\varepsilon$ \\
\hline $\mathrm{H}_{1} \cdots \mathrm{O}_{3 \mathrm{a}}$ & 0.0319 & 0.0992 & 0.0821 & $\mathbf{H}_{1} \cdots \mathbf{O}_{1 \mathrm{a}}$ & 0.0385 & 0.0955 & 0.0329 & $\mathrm{H}_{2} \cdots \mathrm{O}_{2 \mathrm{a}}$ & 0.0472 & 0.1517 & 0.0316 \\
\hline $\mathrm{H}_{2} \cdots \mathrm{O}_{2 \mathrm{a}}$ & 0.0288 & 0.0983 & 0.0400 & $\mathbf{H}_{2} \cdots \mathrm{O}_{2 \mathrm{a}}$ & 0.0291 & 0.0872 & 0.0379 & $\mathrm{H}_{4 a} \cdots \mathrm{O}_{3}$ & 0.0283 & 0.0780 & 0.0963 \\
\hline $\mathbf{H}_{3 \mathrm{a}} \cdots \mathrm{O}_{1 \mathrm{a}}$ & 0.0252 & 0.0800 & 0.0452 & & & & & $\mathbf{H}_{1} \cdots \mathbf{O}_{2}$ & 0.0385 & 0.1189 & 0.0321 \\
\hline \multicolumn{4}{|c|}{$\lambda$-Cm-Fl1_a } & \multicolumn{4}{|c|}{$\lambda$-Cm-Fl1_b } & \multicolumn{4}{|c|}{$\lambda$-Cm-Fl1_c } \\
\hline & $\rho_{\mathrm{bcp}}$ & $\nabla^{2} \rho_{\mathrm{bcp}}$ & $\varepsilon$ & & $\rho_{\mathrm{bcp}}$ & $\nabla^{2} \rho_{\mathrm{bcp}}$ & $\varepsilon$ & & $\rho_{\mathrm{bcp}}$ & $\nabla^{2} \rho_{\mathrm{bcp}}$ & $\varepsilon$ \\
\hline $\mathrm{H}_{1} \cdots \mathrm{O}_{1 \mathrm{a}}$ & 0.0305 & 0.0931 & 0.0299 & $\mathrm{H}_{1} \cdots \mathrm{O}_{8 \mathrm{a}}$ & 0.0369 & 0.1211 & 0.0299 & $\mathrm{H}_{1} \cdots \mathrm{O}_{5 \mathrm{a}}$ & 0.0331 & 0.1099 & 0.0089 \\
\hline $\mathrm{H}_{2} \cdots \mathrm{O}_{2 \mathrm{a}}$ & 0.0256 & 0.0947 & 0.0351 & $\mathrm{H}_{2} \cdots \mathrm{O}_{9 \mathrm{a}}$ & 0.0311 & 0.1040 & 0.0351 & $\mathrm{H}_{2} \cdots \mathrm{O}_{1}$ & 0.0375 & 0.1047 & 0.0333 \\
\hline $\mathrm{H}_{6 \mathrm{a}} \cdots \mathrm{O}_{3 \mathrm{a}}$ & 0.0425 & 0.1297 & 0.0328 & $H_{6 a} \cdots O_{3 a}$ & 0.0452 & 0.1307 & 0.0309 & $\mathrm{H}_{6 \mathrm{a}} \cdots \mathrm{O}_{3 \mathrm{a}}$ & 0.0394 & 0.1225 & 0.0333 \\
\hline $\mathbf{H}_{7 \mathrm{a}} \cdots \mathrm{O}_{4 \mathrm{a}}$ & 0.0288 & 0.0953 & 0.0300 & $\mathrm{H}_{7 \mathrm{a}} \cdots \mathrm{O}_{4 \mathrm{a}}$ & 0.0297 & 0.0968 & 0.0278 & $\mathbf{H}_{7 \mathrm{a}} \cdots \mathbf{O}_{4 \mathrm{a}}$ & 0.0278 & $\mathbf{0 . 0 8 3 5}$ & 0.0395 \\
\hline
\end{tabular}

${ }^{a}$ Values of $\rho_{\mathrm{bcp}}$ and $\nabla^{2} \rho_{\mathrm{bcp}}$ in atomic units. ${ }^{b}$ Numbering scheme as in Figs. 4 and 5 


\section{Figure captions}

Fig. 1 Skeletal structure of the fluvastatin anion and $l$-carageenan and $\lambda$-carageenan polymers studied in this work

Fig. 2 Optimized structure of the fluvastatin conformers. For sake of clarity, only the hydrogen atoms eventually involved in hydrogen bond are shown

Fig. 3 Optimized structures of the models of $\boldsymbol{l}$-carageenan $(\boldsymbol{l}-\mathbf{C m})$ and $\lambda$-carageenan $(\lambda$ $\mathbf{C m}$ ). For sake of clarity, only the hydrogen atoms eventually involved in hydrogen bonds are shown

Fig. 4 Optimized structures of the H-bond complexes of $\boldsymbol{l}$-carrageenan model $(\boldsymbol{l}$-Cm) with fluvastatin anion (Fl1). For sake of clarity, only the hydrogen atoms involved in hydrogen bond are shown

Fig. 5 Optimized structures of the H-bond complexes of $\lambda$-carrageenan model $(\lambda$-Cm) with fluvastatin anion (Fl1). For sake of clarity, only the hydrogen atoms involved in hydrogen bond are shown 
Figure 1

Click here to download high resolution image
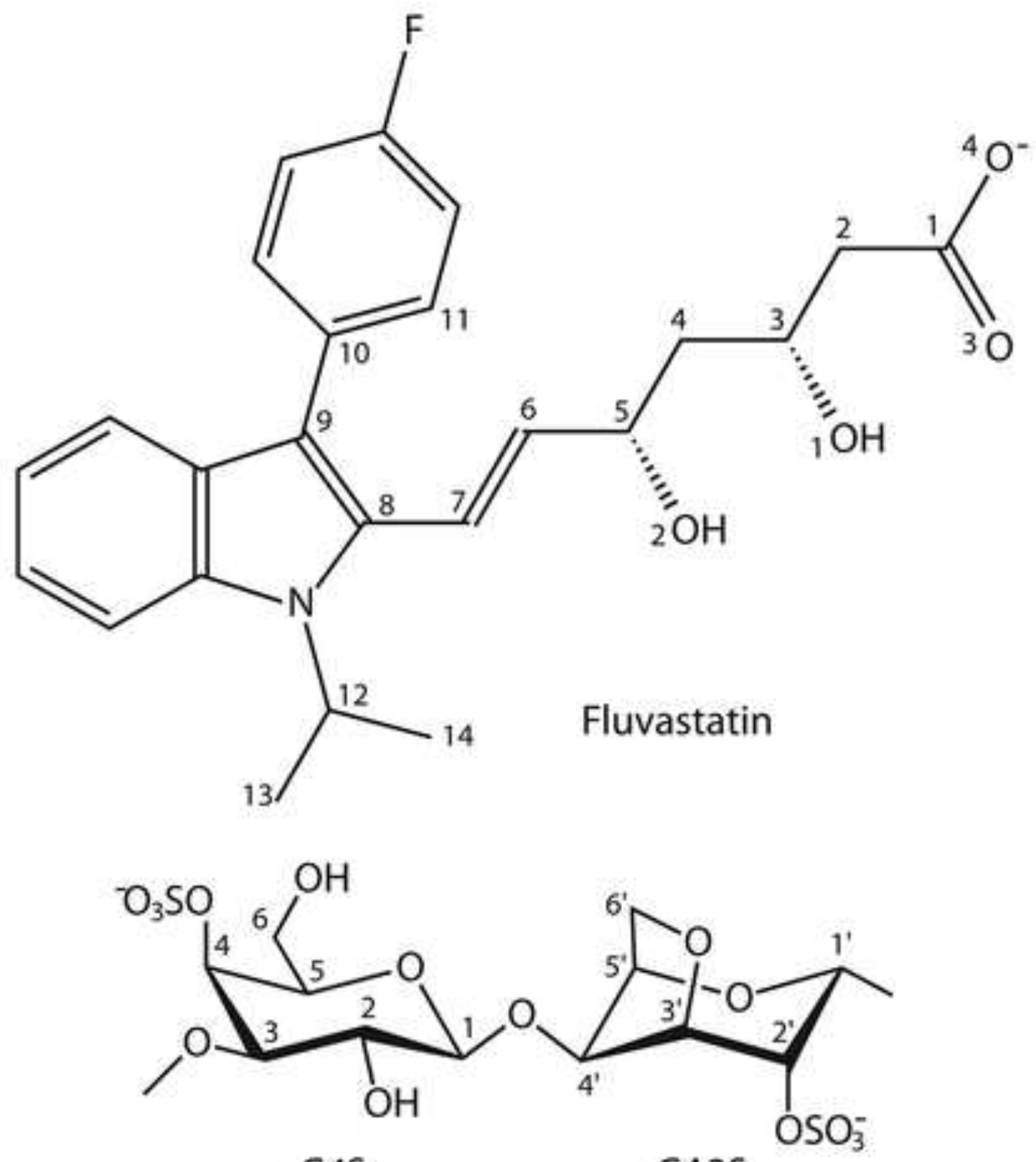

G4S

GA2S

l-carrageenan
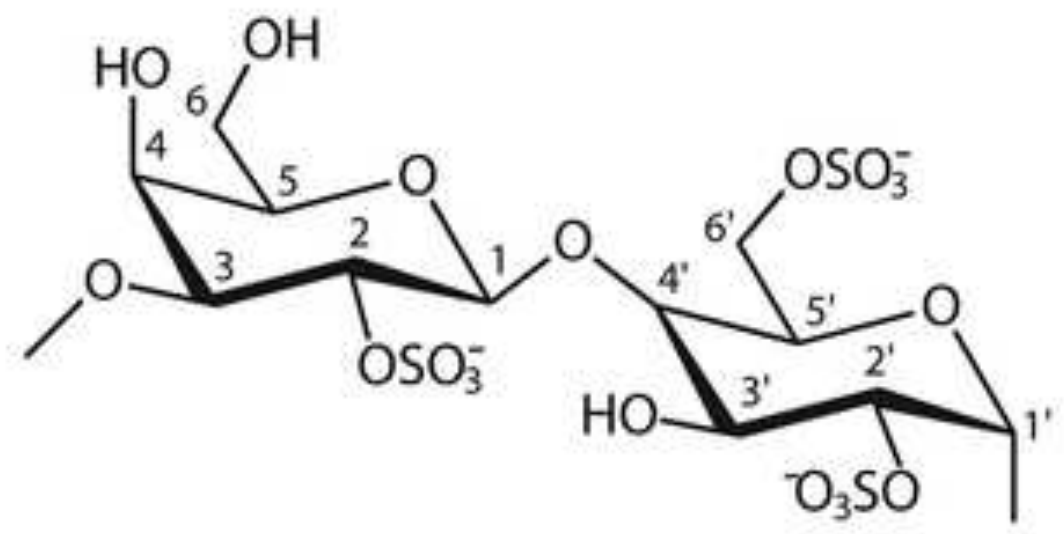

G2S

G2S6S

$\lambda$-carrageenan 
Figure 2

Click here to download high resolution image

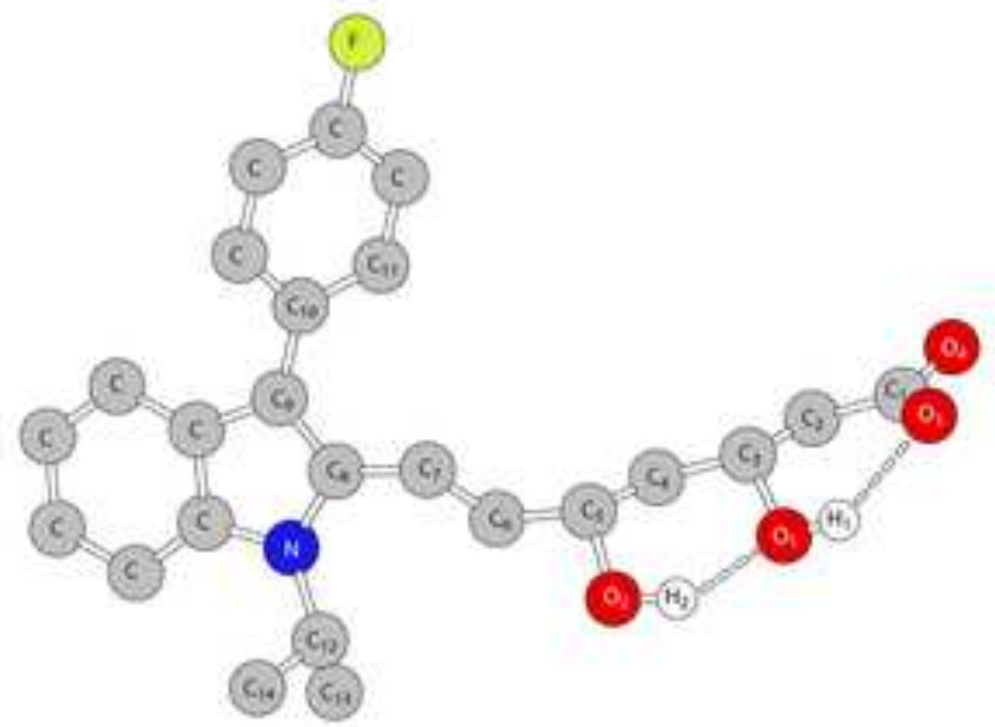

F11

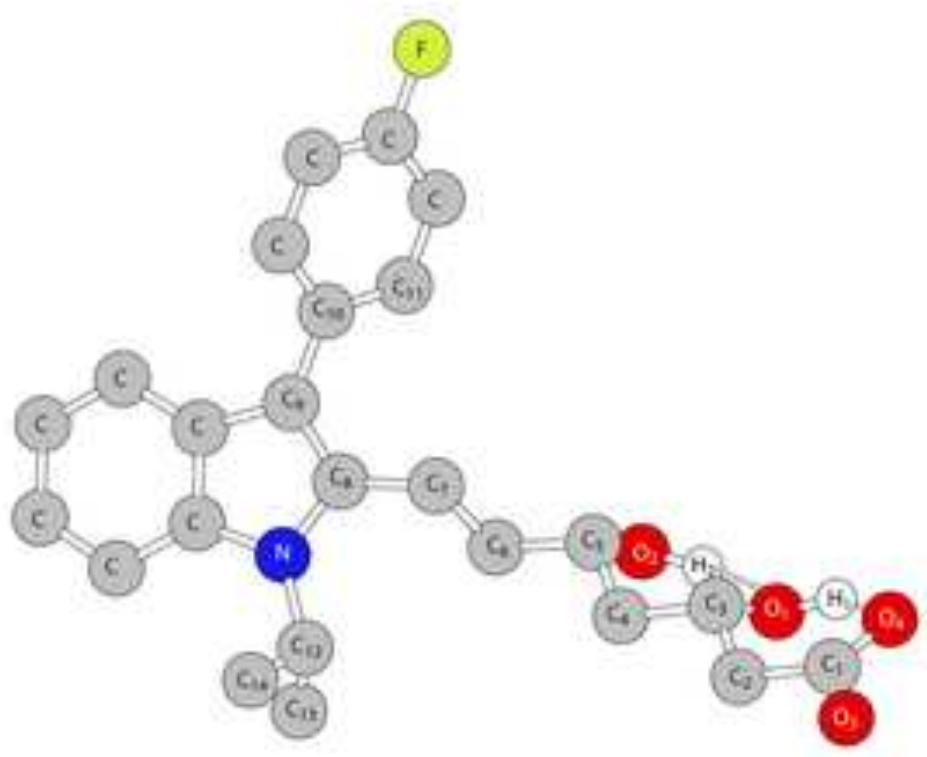

F12

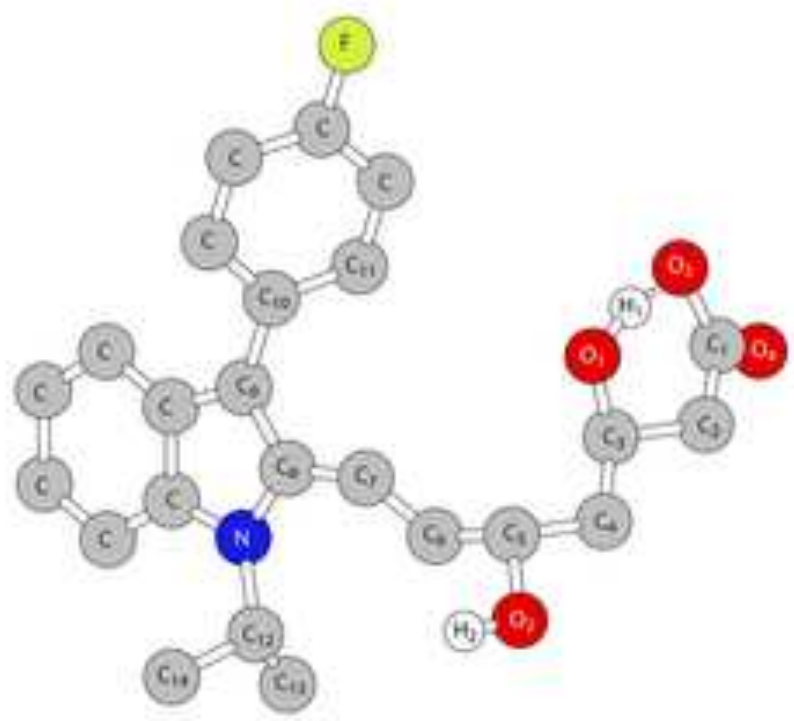




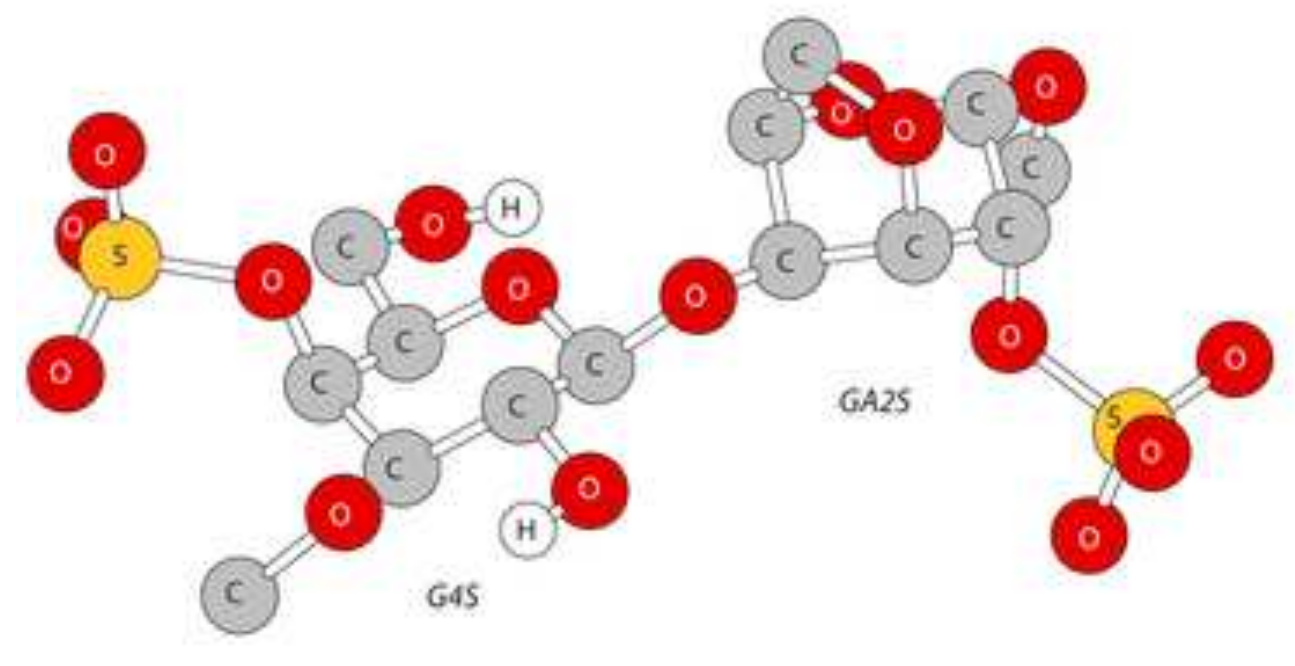

${ }_{l}-\mathrm{Cm}$

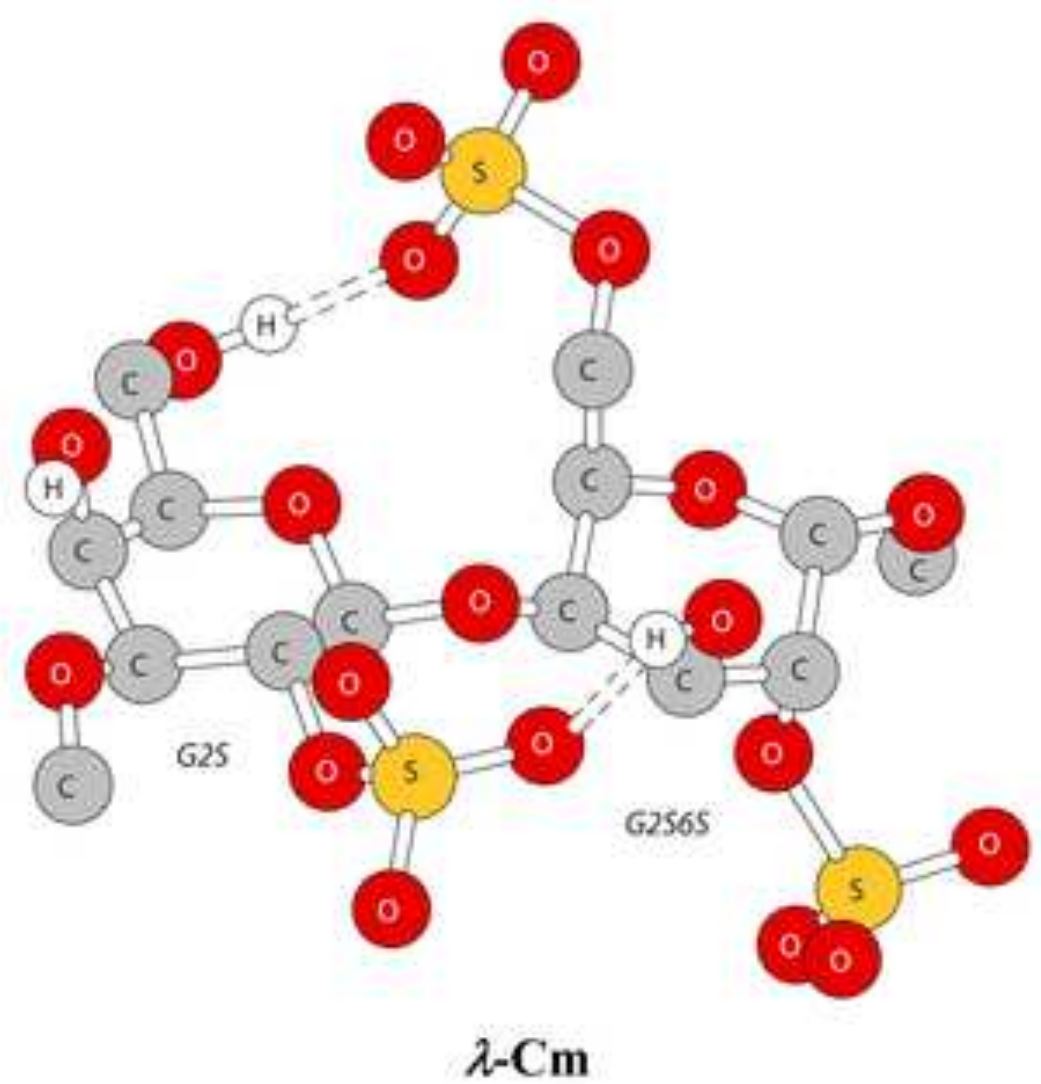


Figure 4

Click here to download high resolution image

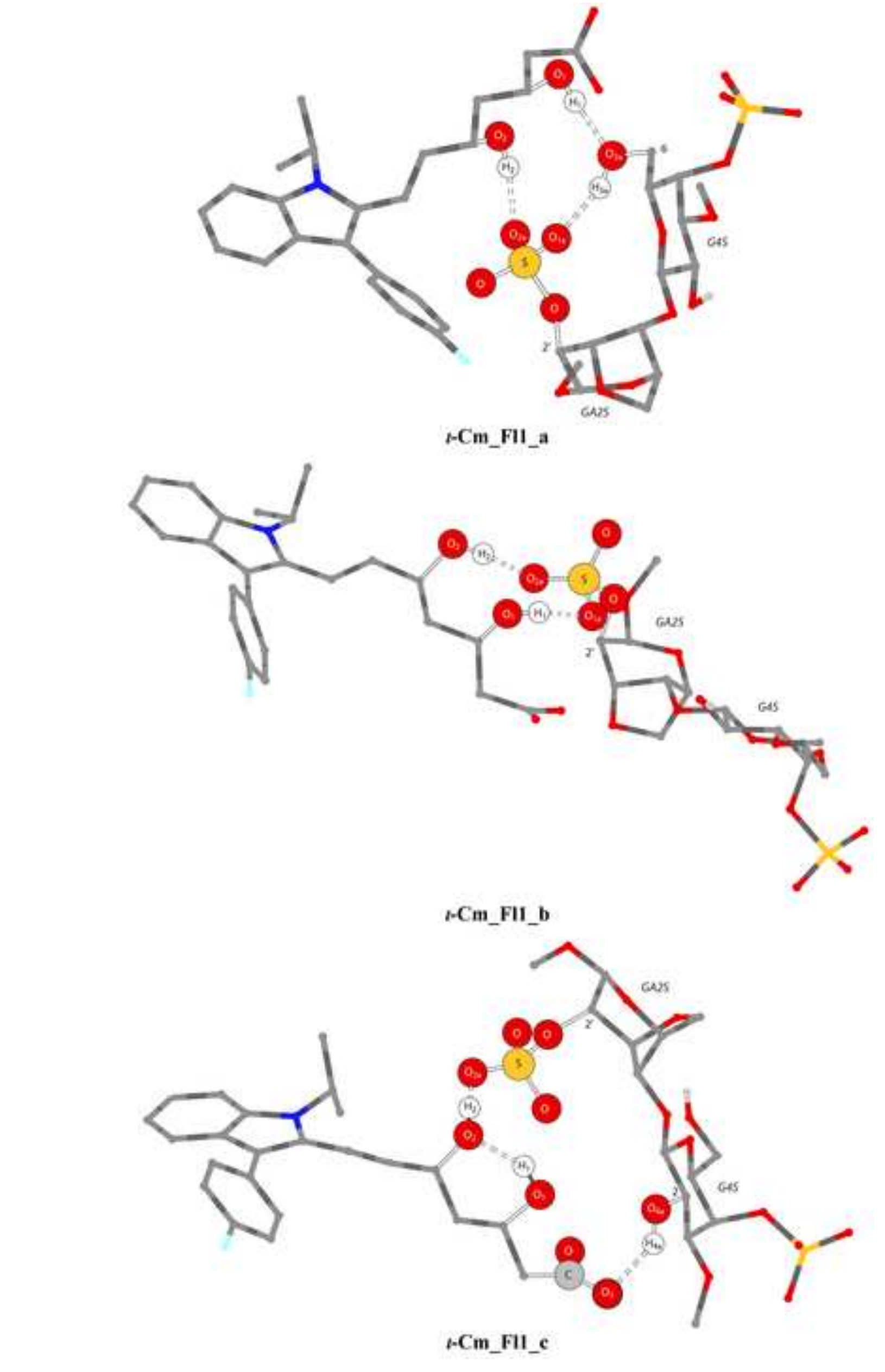

t-Cm_FII_a

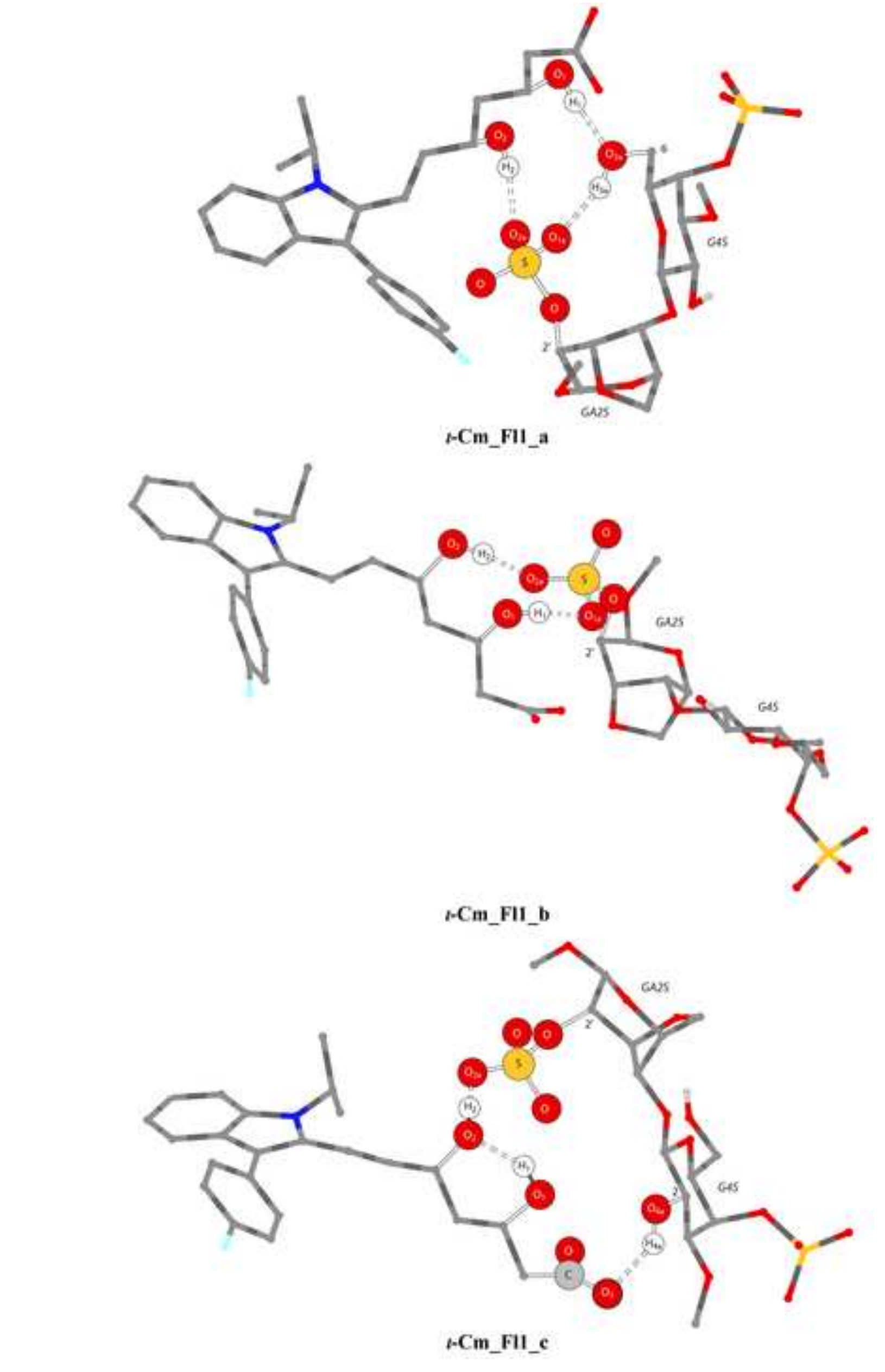

I-Cm_FII_b

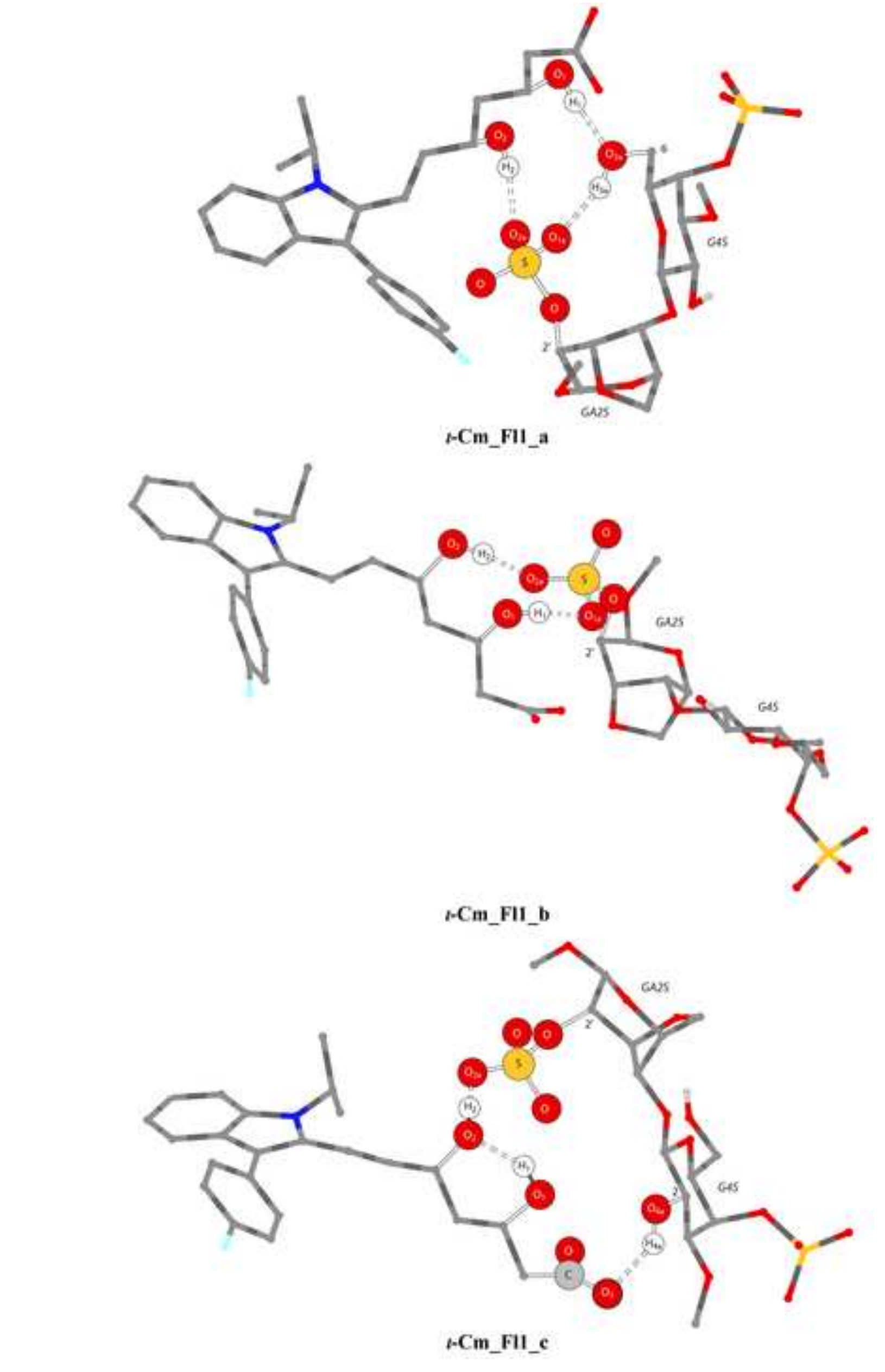

t.Cm_Fli_c

(

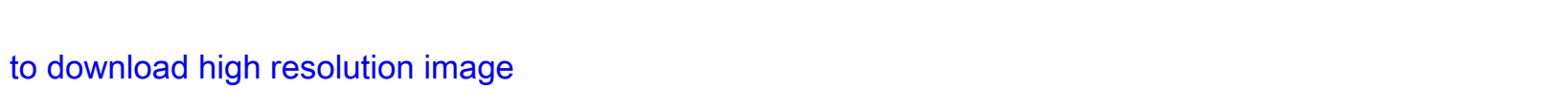




\section{Figure 5}

Click here to download high resolution image
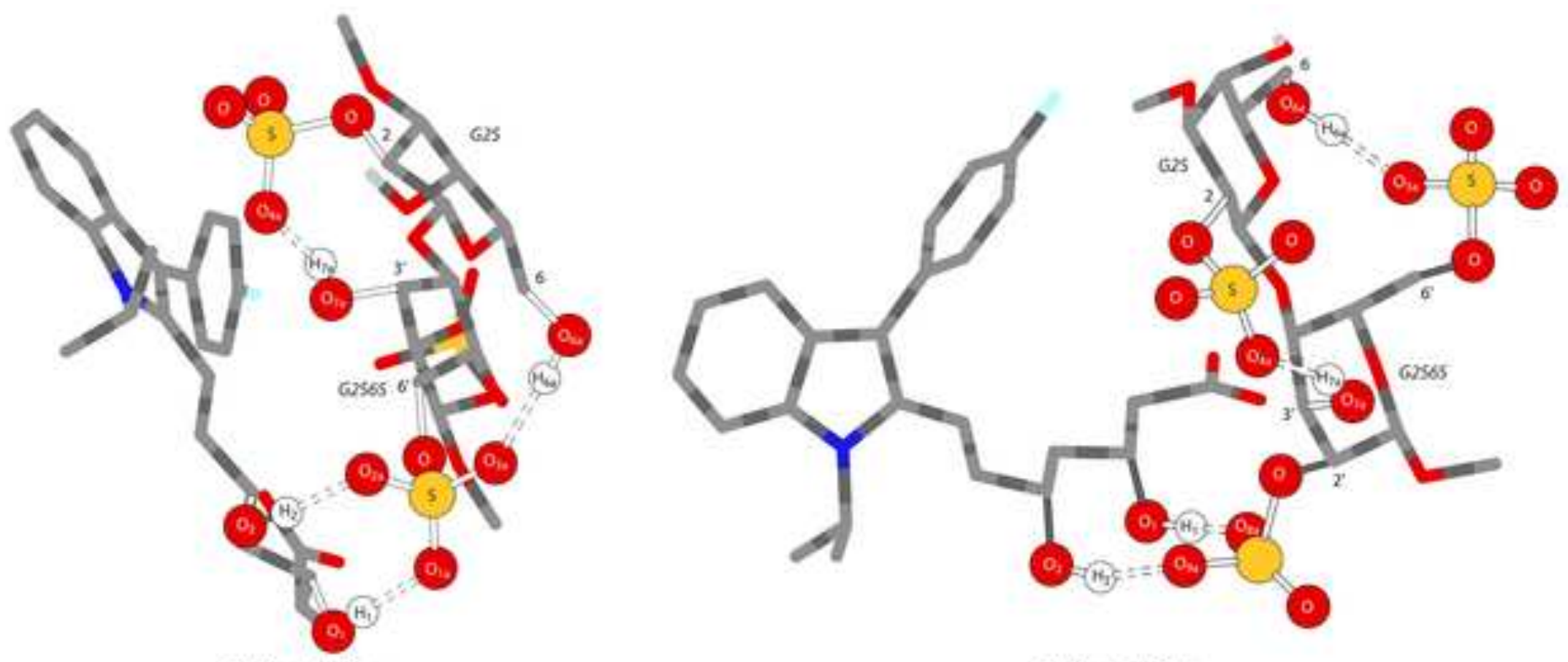

2-Cm_FII_a A-Cm_Fl1_b

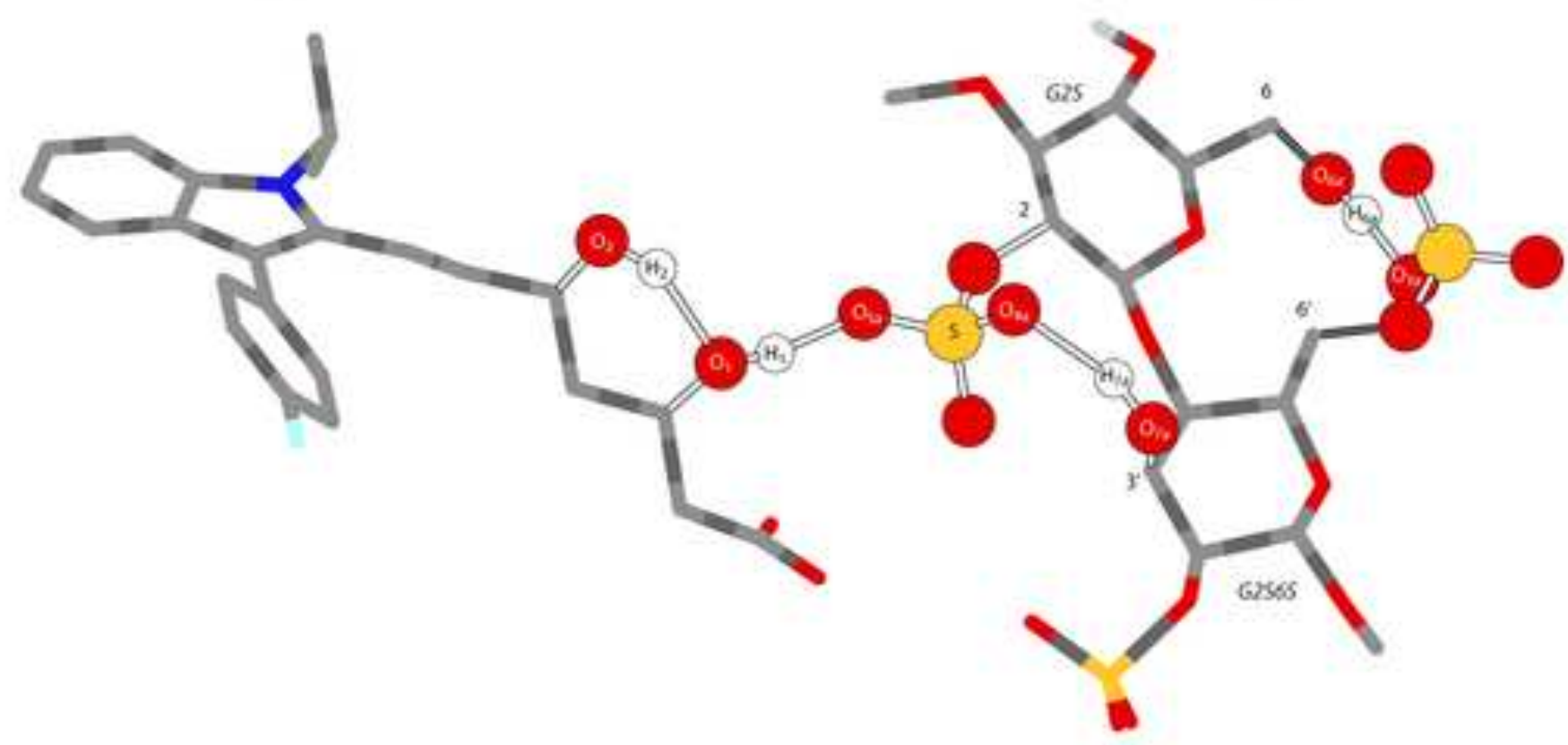

$\lambda-C m \_F I I \_c$ 